\title{
Blended Teaching Mode of Art Course based on Objective Achievement Scale
}

\author{
https://doi.org/10.3991/ijet.v15i13.14987 \\ Guanyu He \\ University of Science and Technology Liaoning, Liaoning, China \\ heguanyu 1886@163.com
}

\begin{abstract}
To solve the problems of students' lack of initiative, inadequacy in research on teaching theories, and imperfection of curriculum evaluation system in the teaching of art course, a new blended teaching mode was built in this study by extracting the advantages of Team-Based Learning (TBL), Problem-Based Learning (PBL) and Case-Based Learning (CBL) in accordance with the teaching characteristics of art course and students' cognitive competence. This mode is designed to focus on teamwork, problem orientation and case analysis in teaching link. This teaching mode consists of online and offline modules, via which teacher releases course materials and assigns classroom tasks and students read the course materials and fulfill tasks online, and students make report on study in the form of group and teacher gives feedback and evaluations offline. An objective achievement scale model with five educational objectives set on the basis of Borich Needs Assessment Model (BNAM) was designed based on development planning and teaching orientation of art course, socio-economic development and job requirements and questionnaire survey on graduates. The conclusion shows that the blended teaching model performs better than conventional teaching model in improving students' academic performance and promoting class enthusiasm and satisfaction with course. With the objective achievement scale model, quantitative evaluation of teaching efficiency can be realized from point, line and plane perspectives, facilitating educators in customizing proper student training program.
\end{abstract}

Keywords-Blended teaching; art course; objective achievement scale; development and application

\section{Introduction}

With the popularization and implementation of all-around education idea and liberal education idea, the public art education of general institutes of higher education in China draws attention from education department, schools and students, and art course becomes an optional and even required course for all-around development available to all students. Nevertheless, the education and teaching of art course are still in the early stage, and it is facing many bottlenecks and problems, such students' lack of initiative, inadequacy in research on teaching theories, and imperfection of curriculum evaluation system. Thus, considering the importance of and problems and difficulties in the 
development of art course, a TBL $+\mathrm{PBL}+\mathrm{CBL}$ blended teaching mode is proposed specific to training plan of art majors in this study, and an objective achievement scale model is built for evaluating the teaching of art course. The research significance is applying blended teaching mode in art course teaching and building objective achievement scale model for quantitative evaluation of curriculum effectiveness, with a view to providing a reference for the reform of teaching mode and evaluation scheme of art course.

The innovation points of this study are as below. Firstly, a blended teaching mode integrating TBL, PBL and CBL is proposed to make use of the advantages of the three modes, for purpose of training students' teamwork skill, problem-solving capability and learning analysis ability. Secondly, the objective achievement scale model makes it realizable to evaluate the completion of training plans of art majors, quantize the training of students' ability, and boost students' innovation and entrepreneurship capabilities after graduation. Thirdly, new media teaching elements have been integrated, including the online teaching program "rain classroom" that supplements offline classroom teaching, and classroom interaction and courseware share that make for the teaching process.

\section{State of the Art}

The TBL, CBL and PBL in the sense of modern pedagogy originated from Harvard Business School, attracted broad attention from the educational circles, and then were applied in several fields of discipline such as medicine, law and commercial science [12]. TBL, short for Team-Based Learning, is an innovative teaching strategy and mode, in which the class form is to divided a class into several teams and leaning and problem solving are realized by means of self-study, thinking, discussion and presentation. Team-based learning sticks to the idea of student-centeredness, hands over the dominancy in learning back to students, and transforms the role of teacher into promotor and facilitator of learning. This teaching strategy and mode is not only helpful to foster students' team spirit and independent study ability, but also proved to be conducive to improve students' academic performance [3]. PBL is a complete set of methods relating to designing learning situation, and also a student-centered teaching mode. Ibrahim et al. [4] applied PBL in medical education at the medical college of Bisha University in the Kingdom of Saudi Arabia, and found this teaching method was conducive to students' knowledge acquisition [4]. Rillero et al. [5] tried to apply PBL in teaching of language courses, combined languages with PBL to form an effective learning environment, and developed a problem-based intensive language learning method on this basis. The results proved that the students accepting PBL teaching method had achieved better learning outcome. Evolving from PBL, CBL [6] is a group discussion teaching method of being based on examples, designing questions associated with the examples, and guiding and inspiring students to make discussions around the questions. Golaghaie et al. [7] combined case study with reflective teaching method to explore the effect of the teaching method on further nursing training. In the teaching, the real medical information of patients and teaching materials relating to case 
management of such type were offered. Participants were guided to do reflection on patient care collectively in accordance with Driscoll' structural reflection model. The research shows that new teaching method can promote students' learning and selfperception ability. In brief, the previous researches on TBL, CBL and PBL mainly are practice research. For example, through researches, Rosenstock et al. [8] insisted that TBL, CBL and PBL should include the following links, namely personal preparation, group discussion, class discussion and after-class summary and reflection. Meanwhile, Harvard Medical School started to apply case teaching method, where teachers introduced real cases in class in teaching process, and asked students to make discussions and analysis to acquire new knowledge and improve their diagnosibility on this basis. The result shows that good effect has been achieved [9]. Later, this teaching method was found to be advantageous in other fields in Harvard University, and was widely adopted. Harvard Business School specially set up the Bureau of Business Research for researching and developing cases [10]. Today, educators are still continuously developing and improving the TBL, CBL and PBL modes.

To sum up, foreign scholars have made a lot of researches on TBL, CBL and PBL modes, and applied these modes in business field, law field and medicine field. Nevertheless, these modes were scarcely applied in the field of art education. Kruse et al. [11] designed an online music teaching method, and applied it in music teaching in combination with five representative folk/traditional music websites on YouTube. It is found that this method involves various teaching forms, has the functions of auditory strengthening, modeling, technical guidance and physiological prompt, and has received positive evaluation from users. Al-Ghawanmeh [12] applied a new musical analysis software in Arabian song teaching in combination with case teaching method, and emphasized analysis, visualization and performance capabilities of music software in his research. It was found that the overall favorability rate of students to this teaching mode reached up to $82.3 \%$, and most students considered this mode was conducive to enhancing their learning ability. Meanwhile, there are lots of Chinese literatures concerning art course teaching in colleges and universities. Reaearches [13-14] considered that there should be a teaching platform to facilitate course teaching, the platform should be associated with the MOCC library in China, and the teaching materials should be updated timely, so as to improve college students' comprehensive quality. Rillero et al. [15] suggested to adopt a blended teaching mode for art course, and apply it in shape-up exercise teaching of college students. The research was completed via questionnaire survey on students, and showed that the blended teaching mode was conducive to improving students' personal academic performance and teamwork performance. Notwithstanding, researchers, through questionnaire survey on and interview with teachers and students, found that the common problems of art course included difficulty in arousing students' initiative, inadequacy in research of teaching theories, unevenness of professional competence of teachers, and imperfection of curriculum evaluation system [16].

Based on this, the outcomes of this study includes combining TBL, PBL and CBL, revising and supplementing the teaching methods in accordance with the teaching characteristics of art course and cognitive characteristics of students, and applying it in art course of universities and colleges; having built an objective achievement scale 
model based on graduate needs as the evaluation criterion for new teaching methods, with a view to providing a new idea for art teaching.

\section{Blended Teaching Mode Based on Objective Achievement Scale}

\subsection{Design scheme of blended teaching mode for course teaching}

The blended teaching mode integrates itself with the advantages of TBL, PBL and $\mathrm{CBL}$, and emphasizes teamwork, problem-orientation and case analysis in various teaching links. The design plan shown in Fig. 1 takes both online learning and offline teaching into account, and contains evaluation and reflection links of teaching situation. Teachers' lesson preparation design consists of online part and offline part. Via the online learning section, teachers release teaching materials and assign classroom tasks via the "Rain Classroom", and students read the materials and fulfill the tasks. For the difficult and main points of tasks, teachers make themselves available online for communication and question answering, and students can raise questions and make discussions online. Via the offline teaching section, students can make a report on study in the form of team, and teachers give feedbacks to students, evaluate the learning outcomes of each team, and help students consolidating and internalizing knowledge. Besides, teachers make evaluation on students based on students' online academic performance and usual performance.

In this design plan, TBL teaching mode is embodied by that students make reports on study in the form of team; that teachers assign tasks in the form of case or question, students conduct learning activities after reading materials, and teachers and students make communications and discussions about main points and difficult points reflects the features of PBL and CBL.

Online learning

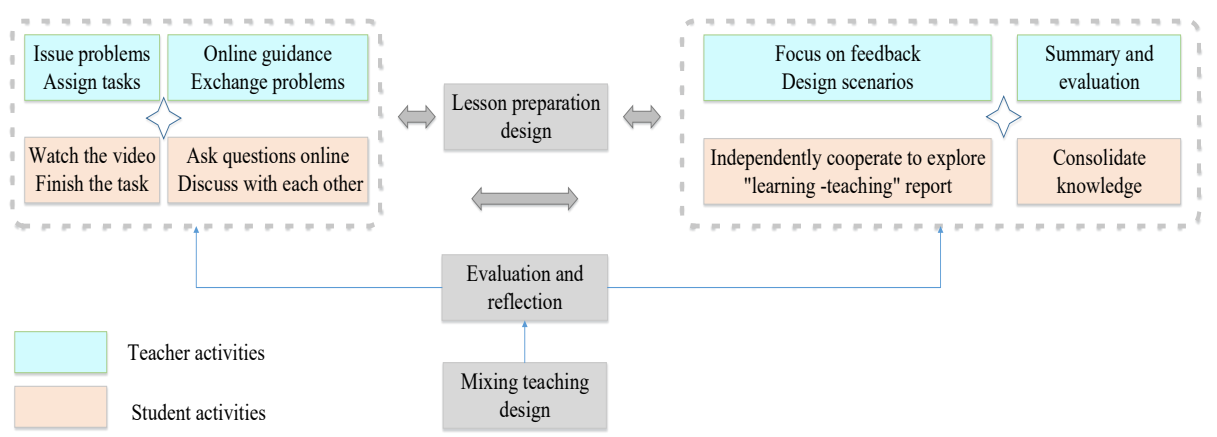

Fig. 1. Blended teaching design 


\subsection{Implementation plan of blended teaching mode in art course}

The blended teaching mode consists of nine modules, as below. Module

(1) defines teaching objectives, which is the leading part of this mode; module

(2) is for building learning team; module

(3) specifies that cooperative principles are the organization mode and rules and requirements of this teaching mode; module

(4) is for determining main problems; module

5 is for analyzing problems in a cooperative way; module

(6) is for determining the solutions; module

(7) is for application of classical cases as the implementation way of this teaching mode; module

(8) is about completion state of questions; module

(9) is about evaluation of learning outcome, which is the summary part of this teaching mode

By this mode, learning points are divided into nine modules, and the nine modules are combined rationally to make them closely linked with one another.

In addition, the second part of Fig. 1 shows tasks to be fulfilled by teachers and students in detail. Teachers should refine knowledge points, design art cases, and guide students' learning. Students should build learning team, make discussions around the questions designed by teacher, and form a report for submission and exchange. After the whole process of the blended teaching mode is completed, both teachers and students need to make reflections and summaries, and teachers also need to check and evaluate students' learning state and quantize students' classroom performance and artistic merit.

The key to the blended teaching mode is to tap the guiding role of questions or cases in learning, and arouse students' initiative of and enthusiasm for learning. This implementation plan has three features. Firstly, students become the leading role in teaching; secondly, teachers make course design based on a complete real case and a set of systematic specific questions, and encourage students to acquire relevant knowledge and solve problems initiatively; thirdly, teachers are aiming to create a reallife situation to stimulate students to make independent thinking under a situational context, and encourage students to air their views. For purpose of this study, AVCON online music class is relied on. This online music class is AVCON online class teaching created by Yidan Technology relying on advanced audio and video technology and internet information technology in combination with distance education system. AVCON online class can truly simulate classroom teaching, via which students can watch intelligent FIND piano under the operation of teacher and cooperate with teacher via their own intelligent pianos perfectly. Moreover, students can turn into silent mode for exercise or discussion while teacher giving lessons, so that teacher and students will not disturb each other. Teacher also can control the FIND piano of each student separately via the main console, to learn about students' learning condition and give guidance promptly. The on-site teaching situation is as shown in Fig. 3. 
Paper-Blended Teaching Mode of Art Course based on Objective Achievement Scale

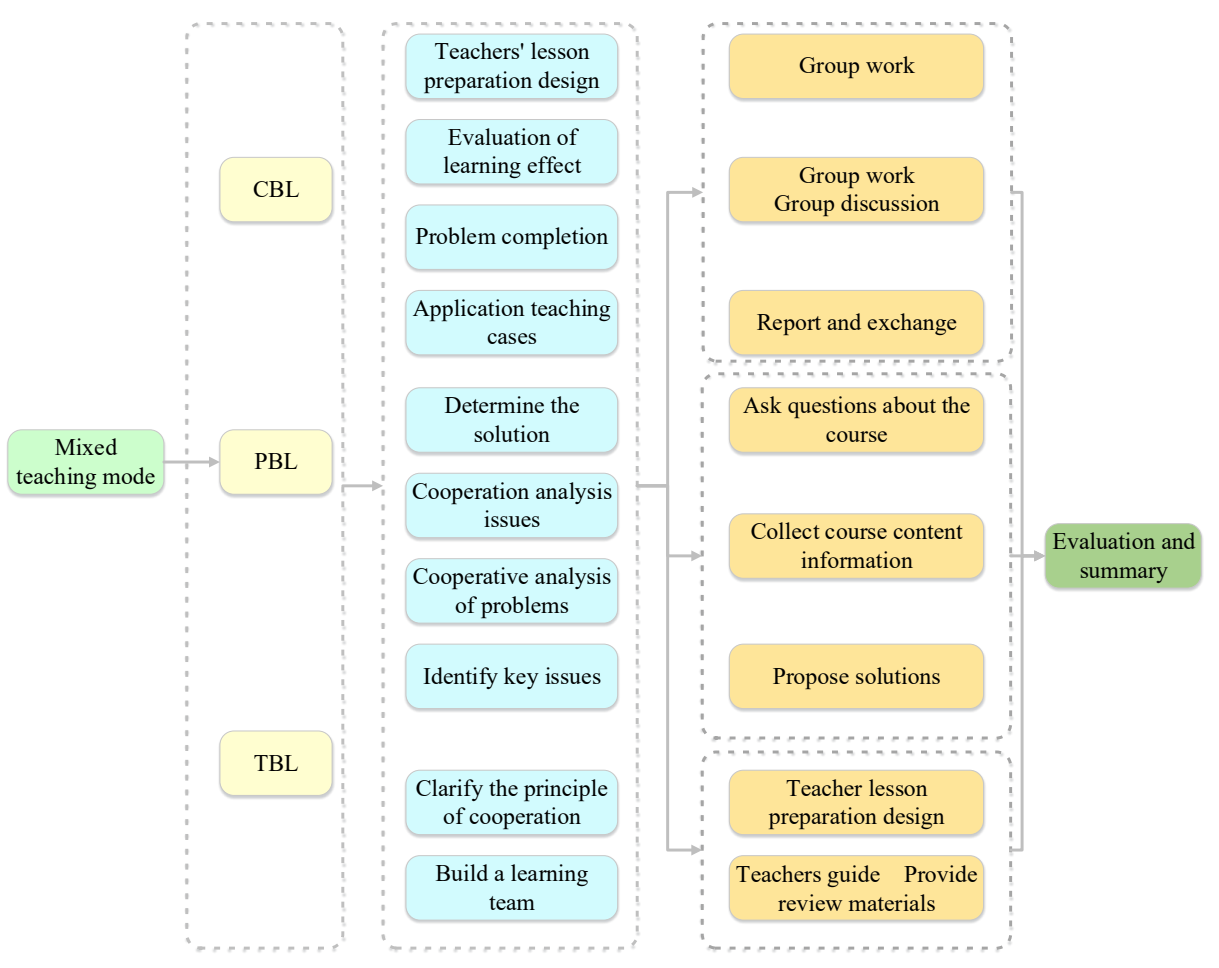

Fig. 2. Blended teaching mode process

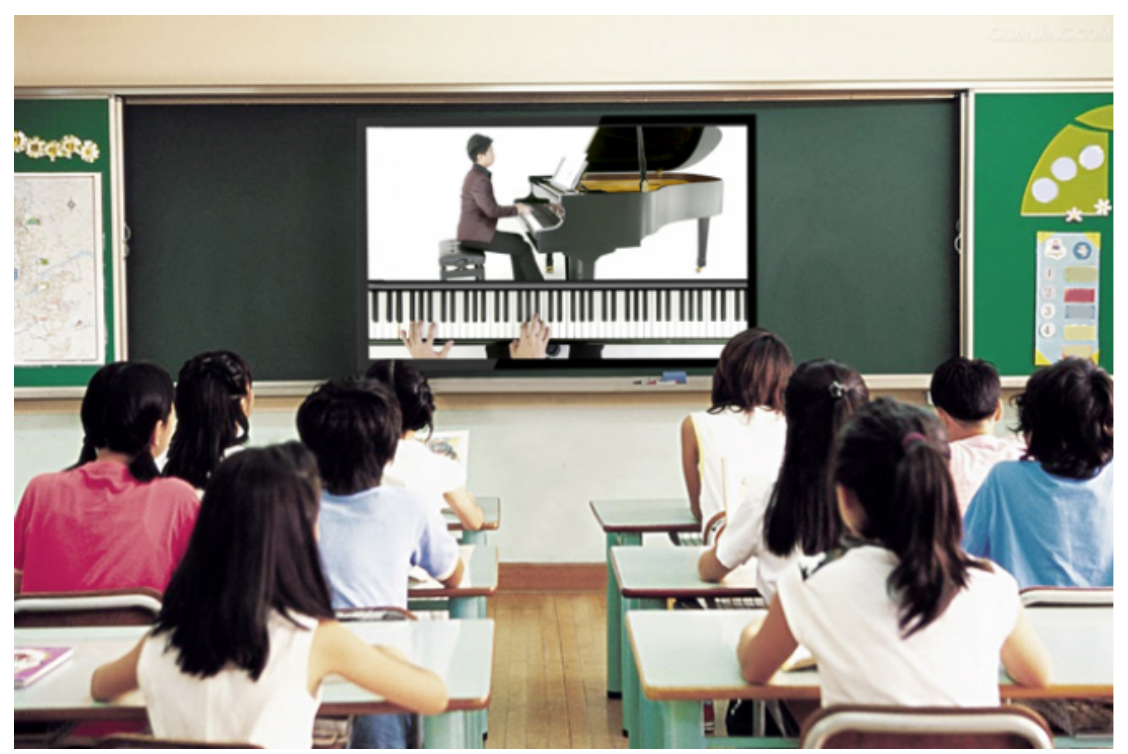

Fig. 3. Application of blended teaching mode in AVCON online music class 


\subsection{Implementation plan of objective achievement scale model in art course}

Objective achievement scale model: Professor Borich of the education system laboratory of the University of Texas at Austin proposed the famous Borich Needs Assessment Model (BNAM) in 1980. BNAM is a method of asking graduates as respondents about importance perception of a certain skill or objective and their mastery degree or realization degree of the skill or objective in the form of questionnaire, with a purpose of determining whether it is necessary to offer training on this skill or if the objective has been attained based on the difference between the perception and real mastery degree. If a specific need (skill or objective) is of great importance, but the respondent has possessed the need (proficient in or master), then the respondent may consider he/she scarcely has such need. In this case, it may happen that an important need doesn't receive sufficient attention. Thus, for a needs assessment model, the difference value between the importance perception and the real mastery degree should be corrected based on importance perception. According to this principle, Borich model is evaluated by calculating the mean weighted difference score (MWDS) in mathematical expression.

The computational formula of MWDS is:

$$
B D N=\sum\left[I^{*}(I-C)\right] / N
$$

Wherein, I is the importance level of a certain skill (or objective) considered by respondent, $\mathrm{C}$ is the mastery level of this skill (or objective) of respondent, $\mathrm{N}$ is the number of sample observations, and $I^{*}(I-C)$ is the value of weighted difference scores.

MWDS can be obtained with the formula. If MWDS is a large positive number, it indicates that the skill (or objective) is in bad need but the real investment in it is insufficient, suggesting that the fostering of this skill needs to be strengthened or the training objective has not be achieved yet; if MWDS is a large negative number, it indicates that the investment in the training of this skill is quite sufficient, or the training objective has been completely achieved; if MWDS is approximate to 0 (ranging from 0.5 to 0.5 ), it indicates that the investment in the training of this skill is sufficient, or the training objective has been achieved.

Objective weighting method: Borich model relates to a subjective weighting method, and is realized based on scores. Objective weighting method is to determine weight according to the correlation of indicators or the degree of variation of indicator values to realize evaluation of objective achievement of course. The below presents the variation coefficient method of objective weighting method[7].

Suppose that $\mathrm{m}$ evaluation results are drawn on $\mathrm{n}$ courses, and the original data matrix is $X=\left(x_{i j}\right)_{n \times m}$, wherein $i=1,2, \ldots, n, j=1,2, \ldots, m$.

$$
\overline{x_{j}}=\frac{1}{n} \sum_{i=1}^{n} x_{i j}
$$




$$
\sigma_{j}=\sqrt{\frac{1}{n-1} \sum_{i=1}^{n}\left(x_{i j}-\overline{x_{j}}\right)^{2}}
$$

The variable coefficient is

$$
V_{j}=\frac{\sigma_{j}}{\left|\overline{x_{j}}\right|}
$$

And the weight coefficient is

$$
W_{j}=\frac{V_{j}}{\sum_{j=1}^{m} V_{j}} .
$$

The variation coefficient method highlights the relative change scope of indicators, namely the degree of variation. According to the purpose of objective achievement evaluation of course, large value of variation coefficient ${ }^{V_{j}}$ means the variation of the ${ }^{j}$ th indicator (evaluation result of the ${ }^{j}$ th method) on different objects is large, and the distinction degree is high (the capability of object distinguishing is strong), so importance should be attached.

\subsection{Implementation plan of blended teaching mode based on objective achievement scale model in art course}

Training objective setting: The training objectives of art course determined according to the development planning and teaching orientation of art course and socioeconomic development and job requirements include:

Objective 1: To develop humanity attainment and professional artistic foundation

Objective 2: To obtain experience of project implementation and management, and become competent for acting as project manager

Objective 3: To develop practical application ability and real case coping capacity in the field of culture creativity

Objective 4: To develop a thinking model and basic skills of innovation and entrepreneurship

Objective 5: To form good professional ethics

Questionnaire design: A Likert 5 point scale was formulated for the five training objectives above based on the objective achievement scale model, as shown in Table 1. The surveyed graduates were asked to select a number from 0 to 4 to score the importance degree and mastery degree of the five options. Large value corresponds to high degree. 0 indicates no importance at all (or not achieved at all), and 4 indicates high importance (or completely achieved). 
Table 1. Questionnaire on training objective achievement

\begin{tabular}{|l|c|c|c|c|c|c|c|c|c|c|}
\hline \multirow{2}{*}{ Objective option } & \multicolumn{4}{|c|}{ Importance to personal development } & \multicolumn{3}{c|}{ Mastery degree of the objective } \\
\cline { 2 - 12 } & Low & & & & High & Low & & & High \\
\hline Objective 1 & 0 & 1 & 2 & 3 & 4 & 0 & 1 & 2 & 3 & 4 \\
\hline Objective 2 & 0 & 1 & 2 & 3 & 4 & 0 & 1 & 2 & 3 & 4 \\
\hline Objective 3 & 0 & 1 & 2 & 3 & 4 & 0 & 1 & 2 & 3 & 4 \\
\hline Objective 4 & 0 & 1 & 2 & 3 & 4 & 0 & 1 & 2 & 3 & 4 \\
\hline Objective 5 & 0 & 1 & 2 & 3 & 4 & 0 & 1 & 2 & 3 & 4 \\
\hline
\end{tabular}

Evaluation on training objective achievement: MWDS was calculated with Formula (1) after collecting the questionnaires. Since large value of MWDS means high degree of need (namely training objective) underachievement, then the achievement scale of training objectives can be obtained by sorting MWDS values from small to large, as shown in Table 2. According to the table, the number of 1 represents the highest degree of achievement, and 5 represents the lowest degree of achievement.

Table 2. Training objective achievement scale

\begin{tabular}{|c|l|c|}
\hline $\begin{array}{c}\text { Order of achievement } \\
\text { degree }\end{array}$ & \multicolumn{1}{|c|}{ Objective option } & MWDS \\
\hline 1 & Objective 1: Humanity attainment and professional foundation & -0.07 \\
\hline 2 & Objective 2: Project experience and manager role & 0.15 \\
\hline 3 & Objective 5: Professional ethics & 0.23 \\
\hline 4 & Objective 3: Application ability and coping capacity & 0.56 \\
\hline 5 & $\begin{array}{l}\text { Objective 4: Thinking and skills of innovation and } \\
\text { entrepreneurship }\end{array}$ & 0.84 \\
\hline
\end{tabular}

According to Table 2, the degree of achievement of Objective 1 is highest, and that of Objective 4 is lowest. This suggests that art majors have solid humanity attainment and professional foundation; the good performance of Objective 2 is attributed to that art majors attach importance to practice; the low degree of achievement of thinking and skills of innovation and entrepreneurship indicates that more attention should be paid to this objective in talent training in future, and the reason may be that schools seldom have innovative and entrepreneurship projects relating to arts and provide poor creation atmosphere, and students are offered with few trainings or exercises.

\section{$4 \quad$ Teaching Example and Effect}

\subsection{Teaching example}

The teaching process based on objective achievement scale model is divided into three stages: planning, implementation and evaluation. After one teaching period is completed, feedback can be made by analyzing achievement data and optimization can be conducted on this basis. The whole teaching process can be shown with the figure 4: 


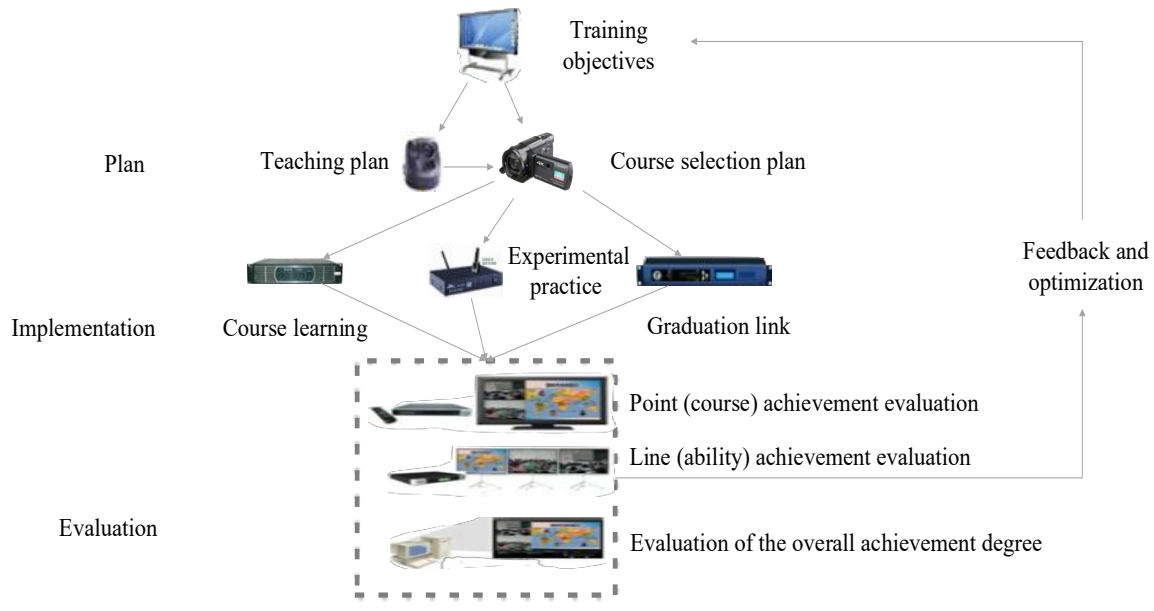

Fig. 4. Teaching process based on objective achievement scale model

The below is about the implementation method of objective achievement scale model. An objective achievement scale model contains three types of elements: student course degree of achievement, competent degree of achievement and total degree of achievement, which are used to quantitatively represent single course, single capability and comprehensive training quality and result respectively[9].

Student course degree of achievement: Student course degree of achievement (SDA) is defined as the degree of the achievement (such as score) made by a student in a course coinciding with the training program requirements.

The computational formula of SDA is:

$$
S D A=(\text { score } / 100) * 100 \%
$$

Wherein, score means course achievement. The degree of achievement is denoted by a figure ranging from 0 to 1 .

Course degree of achievement (CDA) is defined as the average degree of achievement of all students taking the course, and can be calculated. Wherein, stu is the total number of students taking the course.

Competent degree of achievement: Competent degree of achievement is used to represent the situation where a student acquiring a competence by learning or the achievement of a school in training a certain competence of students. The degree of achievement of each competence is obtained via relevant operations over the competent degree of achievement corresponding to the competence line, which is denoted by competent degree of achievement (CPDA). CPDA can be subclassified into competent student degree of achievement (CPSDA) and competent campus degree of achievement (CPCDA).

Wherein, theory, experiment and practice stand for theory course, experimental course and practice course respectively. ${ }_{1}, r_{2}, r_{3}$ is the proportion of the three types of course on this competence line, and $r_{1}+r_{2}+r_{3}=1$. k refers to the kth course. SDA theory 
refers to the degree of achievement of the kth theory course of a student on this competence line, and $C D A_{\text {theory }}^{k}$ refers to the average degree of achievement of the kth theory course of all students on this competence line. Credit theory refers to total credits of theory courses on this competence line. $C_{c r e d i t}^{k}$ refers to credit of the kth theory course. ${ }^{t_{1}, t_{2}, t_{3}}$ refers to the quantity of theory courses, experimental courses and practice courses respectively. The meaning of other variables can be inferred in the same manner.

Total degree of achievement: Total degree of achievement (TDA) is a quantitative indicator for the degree of achievement of objectives of the whole training scheme. Similarly, TDA is subclassified into TSDA and TCDA. TSDA refers to the degree of achievement of the training objectives made by student through learning at the end of a learning period. TCDA refers to the degree of achievement of the training objectives made through teaching at the end of a learning period. Schools can judge their training quality according to this quantitative indicator.

Wherein, $n$ refers to the number of competence lines, ${ }^{W_{i}}$ refers to the weight of each competence, and $\sum_{i=1}^{n} W_{i}=1$.

With the objective achievement scale model, student/course degree of achievement can be calculated manually or via achievement analytical information system, and competent degree of achievement and total degree of achievement can be calculated out on this basis to analyze the real teaching effectiveness. The situation of specialty education optimization of a school can be figured out by analyzing the variation trend of achievement statistical data of a period, to provide a basis for teaching assessment or specialty reform.

\subsection{Teaching effect}

A control group and an experimental group were set to evaluate the effect of the blended teaching mode on the teaching of art course. The control group received teaching in the conventional mode, in which teacher gives a lesson and students passively take a lesson. The experimental group received teaching in a mode blending $\mathrm{TBL}+\mathrm{PBL}+\mathrm{CBL}$, of which the main activities are teamwork, problem solving and case analysis.

In this study, the SE-PETE scale designed by MartinE•Block was introduced to learn about the level of satisfaction with $\mathrm{TBL}+\mathrm{PBL}+\mathrm{CBL}$ teaching mode and conventional teaching mode of students. The scale consists of four indicators (degree of knowledge acquisition, positive rate of question answering in class, satisfaction with course and learning confidence). Each indicator can be scored 100/70/40/10/0, and the average score of each indicator can be calculated with the scores on each question of all students. 236 copies of scale were given out, 220 copies were collected, and the number of valid questionnaires reached 198, representing an effective recovery rate of $84 \%$.

According to Table 3, the students of the experimental class performed much better than the control class in respect of examination result, personal representation result 
and teamwork result, and the blended teaching mode can help improving the overall performance of students in art course comprehensively. The blended teaching mode is conducive to fully arouse students' enthusiasm for learning, initiative of participating in course teaching and teamwork ability, which is quantitatively reflected by the improvement in the results of art course. Analysis shows that the improvement in examination result of art course is attributed to that this teaching method highlights preparation before class and assignment of learning tasks, so that students are clear about the teaching objectives, can prepare lessons before class purposefully, and develop solutions for class to lay a good foundation for the implementation, learning and acquisition of class content and the review and application of after-class content. This experiment highlights group cooperation. In this experiment, learning teams were built, and evaluation was organized by the unit of team, having enhanced students' cooperative consciousness. Besides, this method can promote students' learning initiative and is conducive to improving students' academic performance.

Table 3. Comparison of performance evaluation of students in art course

\begin{tabular}{|l|c|c|c|c|}
\hline \multicolumn{1}{|c|}{ Group } & Attendance rate & Personal performance & $\begin{array}{c}\text { Teamwork } \\
\text { performance }\end{array}$ & $\begin{array}{c}\text { Overall } \\
\text { performance }\end{array}$ \\
\hline Control group & 83.65 & 79.45 & 77.45 & 79.41 \\
\hline Experimental group & 85.76 & 82.35 & 85.67 & 84.12 \\
\hline
\end{tabular}

According to Table 4, students of the experimental class performed much better than the control class in respect of knowledge acquisition, initiative of question answering in class, satisfaction with course, and learning confidence in knowledge acquisition. The PBL module of the blended teaching mode can help students grasping classroom knowledge more flexibly and thoroughly, and the fully interactive and equal classroom atmosphere can raise students' effort level and satisfaction level. The methods that are based on teamwork, question-orientation and case analysis of the blended teaching mode is conducive to enhancing students' comprehensive abilities. That teacher emphasizes the teaching mode of team competition in teaching can promote the degree of knowledge acquisition while enhancing collective consciousness. Besides, preview beforehand enables students to study purposefully, which is helpful to build students' confidence to answer questions in class. Case-based teaching by showing success stories of artists can help students to set ambitious learning target and is inspiring, so as to raise students' course satisfaction, improve learning effect and increase students' learning confidence.

Table 4. Students' satisfaction with different teaching modes

\begin{tabular}{|l|c|c|c|c|}
\hline \multicolumn{1}{|c|}{ Group } & Knowledge acquisition & Question answering & Satisfaction & Self-confidence \\
\hline Control group & 71.89 & 75.12 & 74.82 & 70.25 \\
\hline Experimental group & 76.45 & 79.75 & 81.72 & 79.25 \\
\hline
\end{tabular}




\section{Conclusion}

To solve the problems of students' lack of enthusiasm and imperfection of teaching evaluation system in the teaching of art course, a blended teaching mode was proposed in this study, and an objective achievement scale model was designed for evaluating the effectiveness of the blended teaching mode. The main conclusions and future expectations of this study are as below.

Comparison between the TBL $+\mathrm{PBL}+\mathrm{CBL}$ blended teaching mode proposed herein and conventional teaching mode shows that the students receiving teaching in the blended mode performed much better than those receiving teaching in conventional mode in respect of examination result, personal presentation, teamwork and overall performance.

The objective achievement scale model built herein, based on the objectives to be achieved by the training plan of art majors, is for quantizing the teaching outcome of art course comprehensively, to further facilitate the teaching for fostering innovative and entrepreneurial students and provide an evaluation scheme for the effectiveness of art course teaching.

The deficiency of this study is that only students were covered, and the blended teaching mode was evaluated from the perspective of student, so that the obtained data is not comprehensive enough. It is supposed to take teachers and schools into account as well.

\section{References}

[1] Li, M.L., \& Ren, Y.J. A multimedia teaching model for "sports statistics" based on arcs motivation theory. International Journal of Emerging Technologies in Learning, 2018, vol. 13(9), pp. 15-28. https://doi.org/10.3991/ijet.v13i09.8972

[2] He, Y.F., Du, X.Y., Toft, E., Zhang, X.L., Qu, B., \& Shi, J.N. A comparison between the effectiveness of pbl and lbl on improving problem-solving abilities of medical students using questioning. Innovations in Education \& Teaching International, 2018, vol. 55(1), pp. 4454. https://doi.org/10.1080/14703297.2017.1290539

[3] Macke, C., \& Tapp, K. Teaching research to msw students: effectiveness of the team-based learning pedagogy. Journal of Teaching in Social Work, 2012, vol. 32(2), pp. 148-160. https://doi.org/10.1080/08841233.2012.668161

[4] Ibrahim, M.E., Al-Shahrani, A.M., Abdalla, M.E., et al. The effectiveness of problem-based learning in acquisition of knowledge, soft skills during basic and preclinical sciences: medical students' points of view. Acta Informatica Medica, 2018, vol. 26(2), pp. 119-124. https://doi.org/10.5455/aim.2018.26.119-124

[5] Rillero, P., Koerner, M., Jimenez-Silva, M., et al. Developing teacher competencies for problem-based learning pedagogy and for supporting learning in language-minority students. Interdisciplinary Journal of Problem Based Learning, 2017, vol. 11(2), pp. 4. https://doi.org/10.7771/1541-5015.1675

[6] Srinivasan M. Comparing problem-based learning with case-based learning: effects of a major curricular shift at two institutions. Fudan Education Forum, 2009, vol. 82(1), pp. 7482. https://doi.org/10.1097/01.acm.0000249963.93776.aa 
[7] Golaghaie, F., Asgari, S., Khosravi, S. Integrating case-based learning with collective reflection: outcomes of inter-professional continuing education. Reflective Practice, 2019, vol. 20(1), pp. 42-55. https://doi.org/10.1080/14623943.2018.1539660

[8] Rosenstock, Jason, \& Sparks, Garrett M. Training physicians for the real world of medicine: administration-based learning. Medical Education, 2016, vol. 50(12), pp. 1189-1191. https://doi.org/10.1111/medu.13077

[9] Hirsh, D., Gaufberg, E., Ogur, B., et al. Educational outcomes of the harvard medical school - cambridge integrated clerkship: a way forward for medical education. Academic Medicine, 2012, vol. 87(5), pp. 643-50. https://doi.org/10.1097/acm.0b013e31824d9821

[10] Kloek, C.E., Borboli-Gerogiannis, S., Chang, K., et al. A broadly applicable surgical teaching method: evaluation of a stepwise introduction to cataract surgery. Journal of Surgical Education, 2014, vol. 71(2), pp. 169-175. https://doi.org/10.1016/j.jsurg.2013.07. $\underline{007}$

[11] Kruse, N.B., Veblen, K.K. Music teaching and learning online: Considering YouTube instructional videos. Journal of Music Technology \& Education, 2012, vol. 5(1), pp. 77-87. https://doi.org/10.1386/jmte.5.1.77_1

[12] Al-Ghawanmeh, F.M., Haddad, R.N. ., Al-Ghawanmeh, M.T. Proposing a Process for Using Music Analysis Software to Improve Teaching Authentic Arab Singing and Ornamenting. International Journal of Humanities and Social Science, 2014, vol. 4(6), pp. 47-56.

[13] Gao, B. Highly Efficient English MOOC Teaching Model Based on Frontline Education Analysis. International Journal of Emerging Technologies in Learning, 2019, vol. 14(6), pp. 138-146. https://doi.org/10.3991/ijet.v14i06.10160

[14] Shukor, N.A., Abdullah, Z. Using Learning Analytics to Improve MOOC Instructional Design. International Journal of Emerging Technologies in Learning, 2019, vol. 14(24), pp. 6-17. https://doi.org/10.3991/ijet.v14i24.12185

[15] Rillero, P., Thibault, M., Merritt, J. et al. Bears in a boat: Science content and language development through a problem-based learning experience. Science Activities Classroom Projects \& Curriculum Ideas, 2018, vol. 55(1-2), pp. 28-33. https://doi.org/10.1080/00368 $\underline{121.2017 .1406323}$

[16] Golaghaie F , Asgari S , Khosravi S, et al. Integrating case-based learning with collective reflection: outcomes of inter-professional continuing education. Reflective Practice, 2018, vol. 20(1), pp. 42-55. https://doi.org/10.1080/14623943.2018.1539660

\section{$7 \quad$ Author}

Guanyu He is an associate professor in the University of Science and Technology Liaoning, Liaoning, China (heguanyu 1886@163.com).

Article submitted 2020-04-19. Resubmitted 2020-05-22. Final acceptance 2020-05-23. Final version published as submitted by the authors. 